\title{
Differential Expression of mRNAs for Neuropeptide Y-related Peptides in Rat Nervous Tissues: Possible Evolutionary Conservation
}

\author{
Vincent A. Pieribone, ${ }^{1,2}$ Lennart Brodin, ${ }^{2}$ Katarina Friberg, ${ }^{1}$ Jonas Dahlstrand, ${ }^{3}$ Charlotte Söderberg, ${ }^{4}$ Dan \\ Larhammar, ${ }^{4}$ and Tomas Hökfelt ${ }^{1}$ \\ 'Department of Histology and Neurobiology, ${ }^{2}$ Nobel Institute of Neurophysiology, and ${ }^{3}$ Department of Medical Chemistry, \\ Karolinska Institutet, S-104 01 Stockholm, Sweden, and ${ }^{4}$ Department of Medical Genetics, Uppsala University, S-751 23, \\ Uppsala, Sweden
}

\begin{abstract}
Neuropeptide $Y$ (NPY) is the only member of its peptide family that has been isolated from the mammalian CNS. We have recently found that two different NPY-related molecules are present in the CNS of a cyclostome, the river lamprey (Lampetra fluviatilis) (Söderberg et al., 1991). Here we show that this is also true for the rat CNS, by demonstrating expression of peptide YY (PYY) mRNA in brainstem neurons distinct from those neurons that express NPY mRNA. Dissimilar oligonucleotide DNA probes complementary to $3^{\prime}$ untranslated regions of the rat PYY, NPY, and pancreatic polypeptide (PP) mRNA were used in in situ hybridization experiments on sections of rat brain and spinal cord, visceral organs, and peripheral nerve ganglia. The PYY probe hybridized with two populations of neurons in the brainstem: one dispersed along the midline in the rostral medulla and another in the lateral caudal medulla (A1 region). No additional labeling was detected in the remainder of the neuraxis. In the periphery, PYY hybridization was seen only in endocrine cells of the colon, and not in sympathetic ganglia or the adrenal gland, suggesting that previous observations of PYY immunoreactivity in these latter structures were due to antibody cross-reactivity with NPY. The NPY probe did not hybridize with cells on the midline region that contains PYY neurons, but it did label large numbers of neurons throughout the neuraxis. No expression of PP mRNA was detected in the CNS. Northern blot analysis failed to detect PYY mRNA in the CNS, further supporting the observation that PYY is only expressed by a discrete collection of CNS neurons. The anatomy of PYY- and NPY-expressing cells in the CNS and gut shows a striking similarity between rat and lamprey (Brodin et al., 1989), vertebrates that diverged evolutionarily about 450 million years ago, suggesting that both peptide systems have been conserved throughout vertebrate evolution.
\end{abstract}

\footnotetext{
Received Sept. 24, 1991; revised Mar. 10, 1992; accepted Mar. 24, 1992.

We thank Prof. Sten Grillner and Dr. Urban Lendahl for their generous support during this project. We also express our thanks to Dr. Andrew Leiter for supplying the PYY cDNA, Dr. V. Verge for providing ganglia, and Ms. Siv Nilsson for technical assistance. Funding was provided by M. Bergvalls Stiftelse, Ảke Wibergs Stiftelse, the Swedish Medical Research Council (Project 2807 and 10378), and the Swedish Natural Science Research Council (project B-BU 8524-308). V.A.P. was supported by grants from the National Science Foundation (INT-8908720) and the Fogarty Foundation and the Swedish Medical Research Council (1 F20 TWO 1586-01)

Correspondence should be addressed to Lennart Brodin, The Nobel Institute for Neurophysiology, Karolinska Institutet, Box 60400, S-104 01 Stockholm, Sweden.

Copyright (C) 1992 Society for Neuroscience $0270-6474 / 92 / 123361-11 \$ 05.00 / 0$
}

The neuropeptide Y (NPY) family consists of three related peptides: pancreatic polypeptide (PP), which was discovered first (Lin and Chance, 1974; Kimmel et al., 1975), and also NPY and peptide YY (PYY). NPY and PYY show over 70\% identity in amino acid sequence, and both share $50 \%$ identity with PP (Tatemoto, 1982; Tatemoto et al., 1982).

While immunocytochemical studies have proposed that all members of the NPY family of peptides are present in the brain, as yct NPY is the only family member that has been isolated from the CNS (Tatemoto et al., 1982). Due to the structural similarities, it has been difficult to distinguish between different PP-related peptides using immunological and chromatographic methods. Thus, the results from different laboratories are in conflict and no less than four different hypotheses have been presented regarding the presence of PP-related molecules in nervous tissues. Based on the cross-reactivity patterns of a range of antisera, Inui et al. (1985) have suggested that genuine PP is present in the brain. Broomé et al. (1985) and Ekman et al. (1986) have proposed that PYY occurs in the CNS, based on immunohistochemical and RIA data. The occurrence of PYYlike immunoreactivity in sympathetic neurons (Häppölä et al., 1990) and the adrenal gland (Gaumann et al., 1989) has also been reported. Tatemoto (1989) has suggested that a novel member of the NPY family may be expressed in the brain. Finally, DiMaggio et al. (1985) and de Quidt et al. (1990; de Quidt and Emson, 1986) have proposed that NPY is the only NPY family member present in the CNS. The latter investigators have presented evidence that the PP-like material that can be distinguished from NPY in chromatographic separation of brain extracts is actually an oxidized form of NPY.

Our recent results from cDNA cloning studies in a cyclostome, Lumpetra fluviatitis, have indeed shown that more than one PPrelated peptide can be expressed in the CNS of a vertebrate (Söderberg et al., 1991). To further analyze this matter in the rodent, we have used the in situ hybridization technique to examine the expression of NPY, PYY, and PP in the nervous system of the rat. Due to the high degree of sequence identity between the translated regions of the NPY, PYY, and PP mRNAs, DNA oligonucleotide probes were made against $3^{\prime}$ untranslated regions of the three mRNAs. These probes showed no significant similarity to each other. In addition, Northern blot analysis of nervous and visceral tissues was done to compare the levels of PYY and NPY mRNA.

\section{Materials and Methods}

Male Sprague-Dawley rats (100-200 gm) were used in all experiments. Animals were housed and cared for in compliance with National In- 

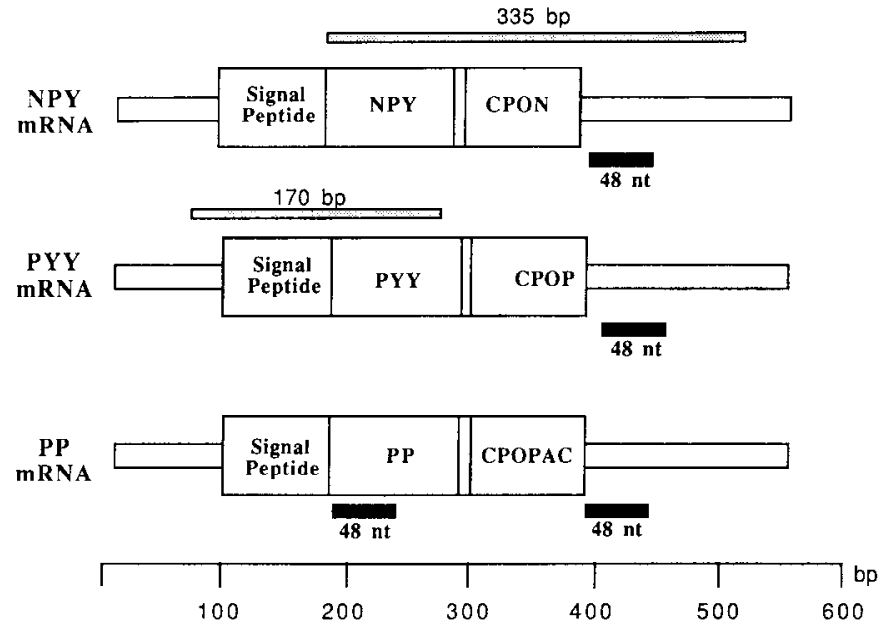

Figure 1. A schematic diagram of the NPY, PYY, and PP mRNAs detailing the locations on the mRNA where the oligonucleotide and cDNA probes were derived from for the present studies. The oligonucleotides (solid bars marked $48 \mathrm{nt}$ below the mRNAs) used in the in situ hybridization studies of NPY, PYY, and PP and Northern blo analysis of PYY and NPY were complementary to regions in the untranslated $3^{\prime}$ ends of the corresponding mRNAs. An additional oligonucleotide DNA probe used for PP in situ experiments was complementary to a portion of the PP peptide-coding region of the PP mRNA. Additional Northern blot analysis was done using $\mathrm{CDNA}$ probes derived from the 5' end of the PYY and NPY mRNA (open bars above the NPY and PYY mRNAs).

stitutes of Health guidelines for the care of laboratory animals. Animals were rapidly decapitated by guillotine, and the brains, peripheral ganglia, and various visceral organs removed and rapidly frozen on dry ice

In situ hybridization. Oligonucleotide probe sequences were selected for optimal GC content (approximately $60 \%$ ) and minimal homology with other known RNA sequences (no eukaryotic sequences in Gene Bank had over $80 \%$ identity) and synthesized on a Pharmacia Gene Assembler. The NPY, PYY, and one of the PP probes were all 48 bases and complementary to $3^{\prime}$ untranslated regions of the rat mRNAs, respectively (Fig. 1). The PYY probe was complementary to nucleotides 357-405. (5'-ACCAAACATGCAAGTGAAGTCGGTGTAGTTAGCACA-TCTCACGGGAGG-3') (Leiter et al., 1987). The NPY probe was complementary to nucleotides 3146-3194 (5'-A TGAGATGTGGGGGGAAACTAGGAAAAGTCAGGAGAGCAAGTTTCATT-3') (Larhammar et al., 1987). Two PP probes were made: one to region 2562-2610 of the rat PP gene (Yonekura et al., 1988), with the sequence 5'-CCCTGA GACCTTGTTTCCCTTCCCCTCCTTTGGATCCCCTTTCCAGAC-3', and one to positions 676-723 the translated region of the mRNA, with the sequence 5'-CTGTTGATGCGTAGCATAGTCCCCCGGGTACATTG GCTCCAGTGGGGC-3'.

The probes were end labeled with ${ }^{35} \mathrm{~S}$-adenosine triphosphate $\left[{ }^{35} \mathrm{~S}\right.$ ATP; New England Nuclear (NEN); approximately $20-40{ }^{35} \mathrm{~S}-\mathrm{ATP}$ moles per mole of oligonucleotide DNA] by combining $80 \mathrm{ng}$ of the probe with $24 \mathrm{U}$ of terminal deoxynucleotidyltransferase (Amersham), ${ }^{35} \mathrm{~S}$ ATP, $2.5 \mu \mathrm{I}$ cobalt reaction buffer (NEN), and $6 \mu \mathrm{l}$ of water. The reaction mixture was incubated at $37^{\circ} \mathrm{C}$ for $2 \mathrm{hr}$, stopped with $0.1 \mathrm{M}$ Tris buffer ( $\mathrm{pH} 8.0$ ), and purified on a Nensorb 20 column (NEN) as directed by the manufacturer.

Fourteen micron serial cryostat sections of various tissues were melted onto Probe-on slides (Fisher). Alternate sections were processed for either PYY, NPY, or PP in situ hybridization (Schalling et al., 1986; Dagerlind et al., in press). Unfixed sections were incubated overnight at $42^{\circ} \mathrm{C}$ in a solution containing (per $\mathrm{ml}$ ) 10 million $\mathrm{cpm}$ of the oligonucleotide probe, $31 \mathrm{mg}$ of dithiothreitol, and $400 \mu \mathrm{g}$ of heat-sheared salmon sperm DNA in a hybridization cocktail containing (per $200 \mathrm{ml}$ ) $40 \mathrm{ml}$ of formamide, $40 \mathrm{ml}$ of $20 \times \mathrm{SSC}(1 \times \mathrm{SSC}$ is $3 \mathrm{M} \mathrm{NaCl}$ and 150 mM sodium citrate), $2 \mathrm{gm}$ of sarcosyl, $20 \mathrm{gm}$ of dextran sulfate, $20 \mathrm{ml}$ of sodium phosphate buffer $(0.1 \mathrm{M}, \mathrm{pH} 7.0)$, and $2 \mathrm{ml}$ of Denhardt's solution $(0.02 \mathrm{M}$ Ficoll, $0.02 \mathrm{M}$ bovine serum albumin, and $0.02 \mathrm{M}$ polyvinylpyrrolidone). Following the incubation, sections were rinsed for $4 \times 15 \mathrm{~min}$ in $1 \times \mathrm{SSC}$ buffer at $55^{\circ} \mathrm{C}$ and then allowed to cool for $1 \mathrm{hr}$, dehydrated in $60 \%$ then $95 \%$ ethanol, and air dried. Sections were dipped in Kodak NTB-2 photographic emulsion and allowed to expose in the dark for between 1 and 4 weeks at $-20^{\circ} \mathrm{C}$. Slides were developed in Kodak D-19 developer ( $2 \mathrm{~min}$ ), rinsed in water, and fixed in Kodak fixer for $10 \mathrm{~min}$. Sections were then rinsed in water for $20 \mathrm{~min}$, dipped in PBS, and coverslipped in a glycerol/PBS solution. Some sections were counterstained with cresyl violet. Sections were observed and photographed on a Nikon Microphoto-FX microscope using dark- and brightfield illumination. Photomicrographs were made on Kodak Panatomic $X$ film. Image analysis of autoradiographic grain densities was performed on an Apple Macintosh IIx equipped with a Dage 72 CCD camera and an Optilab framegrabber card. Software (IMAGE 3.05) was provided by Dr. Wayne Rasband of NIH.

Northern blot methodology. Male rats $(n=26)$ were rapidly decapitated, and the brain and distal gut were removed. The cerebral cortex (frontal lobes), the cerebellum, and the medial medulla oblongata were dissected out and rapidly frozen in liquid nitrogen. Total RN $\Lambda$ was extracted from each tissue using the RNAgents (Promega). PolyA' mRNA was selected from the total RNA using a column containing oligodT attached to an insoluble matrix (Pharmacia, Stockholm, Sweden). Five micrograms of polyA ${ }^{+}$RNA were added to each lane of the gel along with appropriate RNA standards. The RNA was then blotted onto nitrocellulose filters, which were hybridized with either an NPY or a PYY oligonucleotide probe. Probes were end labeled as above except with ${ }^{32}$ P-ATP. Filters were prehybridized overnight in a solution containing the following: $5 \times$ SSC, $5 \times$ Denhardt's solution, $250 \mu \mathrm{g} / \mathrm{ml} \mathrm{salm}$ on sperm DNA, $50 \mathrm{~mm}$ sodium phosphate buffer $(\mathrm{pH} 6.5)$, and $0.5 \%$ sodium dodecyl sulfate. Following the prehybridization, the probes $(2$ $\times 10^{6} \mathrm{cpm} / \mathrm{ml}$ ) were added and the filters hybridized overnight. Both the prehybridization and the hybridization were done at $42^{\circ} \mathrm{C}$. Following hybridization, the filters were washed $2 \times 5 \mathrm{~min}$ in $2 \times \mathrm{SSC}$ at room temperature, and then $2 \times 30 \mathrm{~min}$ in $0.2 \times \mathrm{SSC}$ plus $0.2 \% \mathrm{SDS}$ at $65^{\circ} \mathrm{C}$. Filters were then apposed to autoradiographic film (Amersham $\beta$ Max). The following combinations of blot experiments were done (each on all four types of tissue); polyA ${ }^{+}$RNA with PYY $(n=2)$ and NPY $(n=1)$ oligonucleotide probes, and total RNA with PYY $(n=1)$ and NPY $(n$ =1) $\mathrm{cDNA}$ probes (Fig. 1).

\section{Results}

In situ hybridization using the PYY probe

Cryostat sections at virtually every level of the brain and spinal cord were examined with in situ hybridization. Specific binding of the PYY probe was found only over neurons in the medulla. Sections of the colon processed on the same slides as the brain sections always showed hybridization and were used as a positive control for the hybridization of the PYY probe (see Fig. 3 ). When emulsion-dipped sections were allowed to expose for a short time (i.e., 1 week), specific cellular hybridization was seen only over one collection of neurons at the pontomedullary junction in the brainstem (Figs. $2 ; 3 A, B ; 4$ ). These neurons were found dispersed about the midline directly dorsal to the raphe magnus within and dorsal to the gigantocellular region of the reticular formation. These neurons had a very limited rostrocaudal distribution, being present over approximately $1 \mathrm{~mm}$ along the longitudinal axis approximately from interaural level -2.5 to -1.5 (Paxinos and Watson, 1986). The neurons were always located above the pyramidal tracts and did not extend laterally into the paragigantocellularis pars dorsalis region, and they were generally restricted to the ventral two-thirds of the medulla. In Nissl-counterstained emulsion-dipped sections an accumulation of silver grains was seen over medium-to-large (20-30 $\mu \mathrm{m}$ in long axis) neurons (Fig. 3B). Although double staining was not done, the distribution of these neurons did not appear to correspond with the location of the 5-HT neurons that are found in this region. When dipped sections were allowed to expose for a longer period of time, silver grains could be scen over a small collection of neurons clustered near the nucleus 

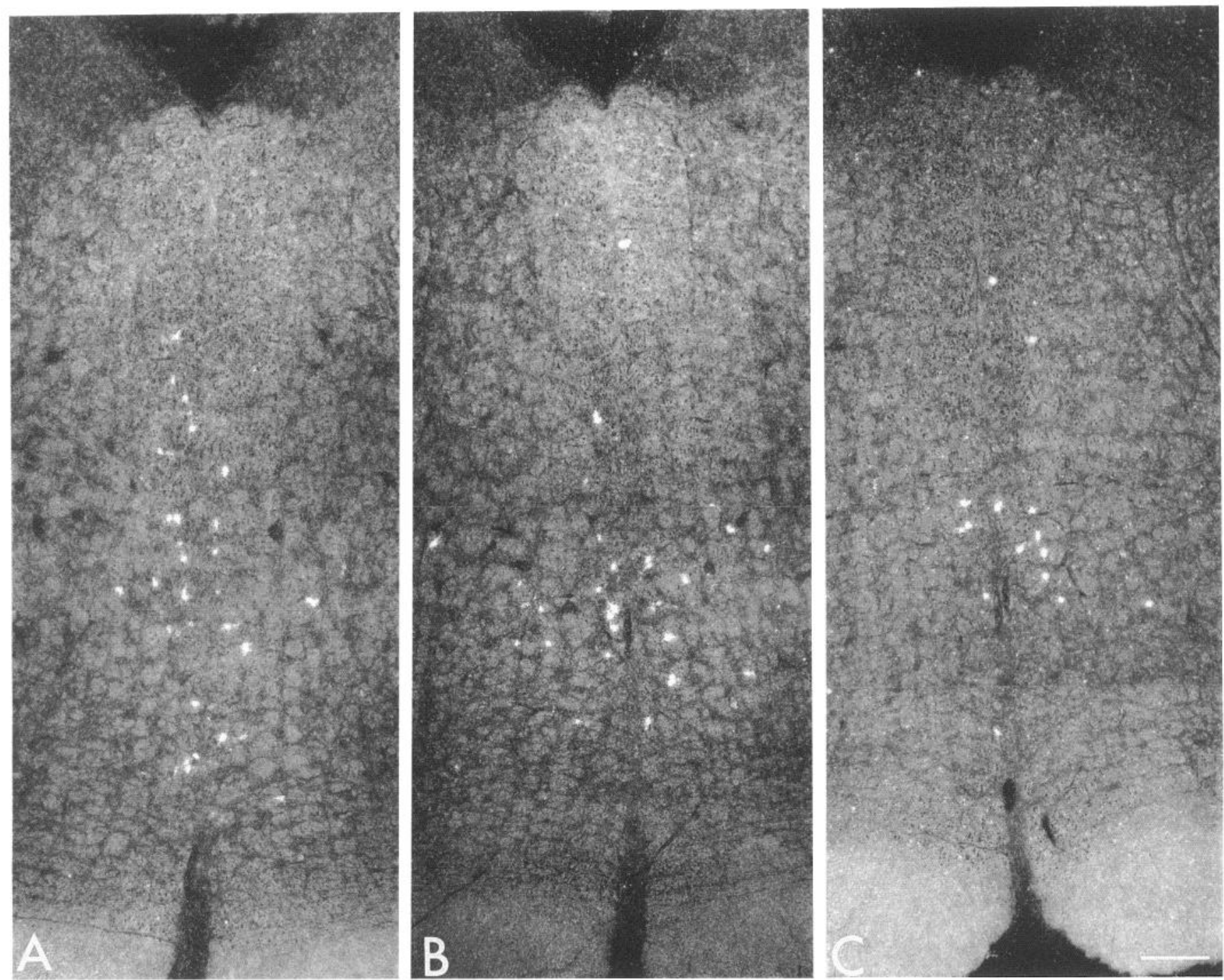

Figure 2. PYY in situ hybridization. A-C, Dark-field photomontages of silver grain collections over neurons on the midline in the rostral medulla on tissue sections hybridized with the PYY oligonucleotide probe. Note that very few cells in the field exhibit specific hybridization. $A$ is caudal and $C$ is rostral. Scale bar, $100 \mu \mathrm{m}$.

ambiguus in the ventrolateral medullary area (near the Al noradrenergic cell group; Figs. $3 C$, 4). These neurons were present at a more caudal level than the midline PYY neurons and consistently showed much less intense hybridization. The labeled neurons were medium to large in size (10-20 $\mu \mathrm{m}$ in diameter). A schematic diagram depicting these two labeled cell groups is shown in Figure 4.

Sections of the intestines (small and large) incubated with the PYY probe revealed numerous intensely labeled cells scattered in the lumen (mucosal layer; Figs. $3 D, E ; 5 C$ ). No cells were seen in the submucosal or surrounding muscular layers of the intestines. Greater numbers of cells were seen in the distal colon (Fig. 3D) than in the rostral small intestines (Fig. 5C), in which fewer luminal cells exhibited hybridization. In addition, hybridization was seen over cells in the pancreas (data not shown). Although it has been previously reported (Gaumann et al., 1989) that PYY-immunoreactive material is present in the adrenal medulla, no specific PYY hybridization was detected anywhere in the adrenal gland (Fig. 5E). Other tissues including lung, trachea, kidney, and liver were examined, but no specific hybridization was found in any of these tissues even following extended exposure times.

Cryostat sections of sympathetic (superior cervical) (Fig. 5A), parasympathetic (nodose), and primary sensory (lumbar dorsal root) ganglia were also incubated with the PYY probe. While a previous report indicated that neurons in sympathetic ganglia exhibited PYY immunoreactivity (Häppölä et al., 1990), no specific hybridization (Fig. $5 \mathrm{~A}$ ) could be detected in any of the above ganglia following extended exposure times ( 4 weeks). Sections of dorsal root ganglia that had the distal afferent processes cut either 7 or $28 \mathrm{~d}$ prior to removal (see below) were also examined for PYY expression. No specific PYY expression was detected in any of these tissues.

The grain density over labeled neurons in sections of the medulla and colon was compared using an image analysis system. After $21 \mathrm{~d}$ exposure of emulsion-dipped sections, midline medullary PYY neurons had 40\%[102.1 \pm 28.1 mean pixel value (out of 256 levels) over cell body of 50 measures \pm SD] 

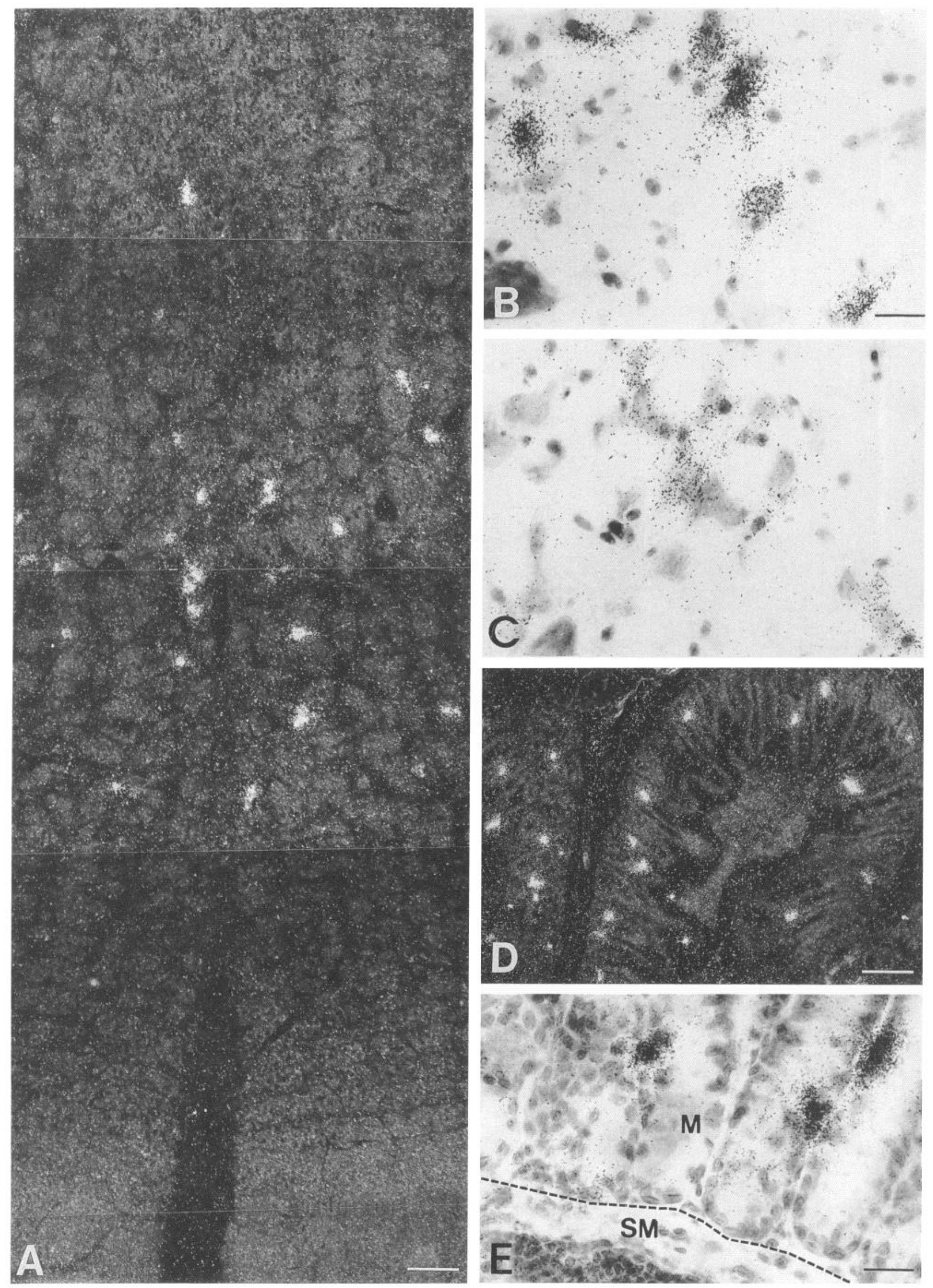

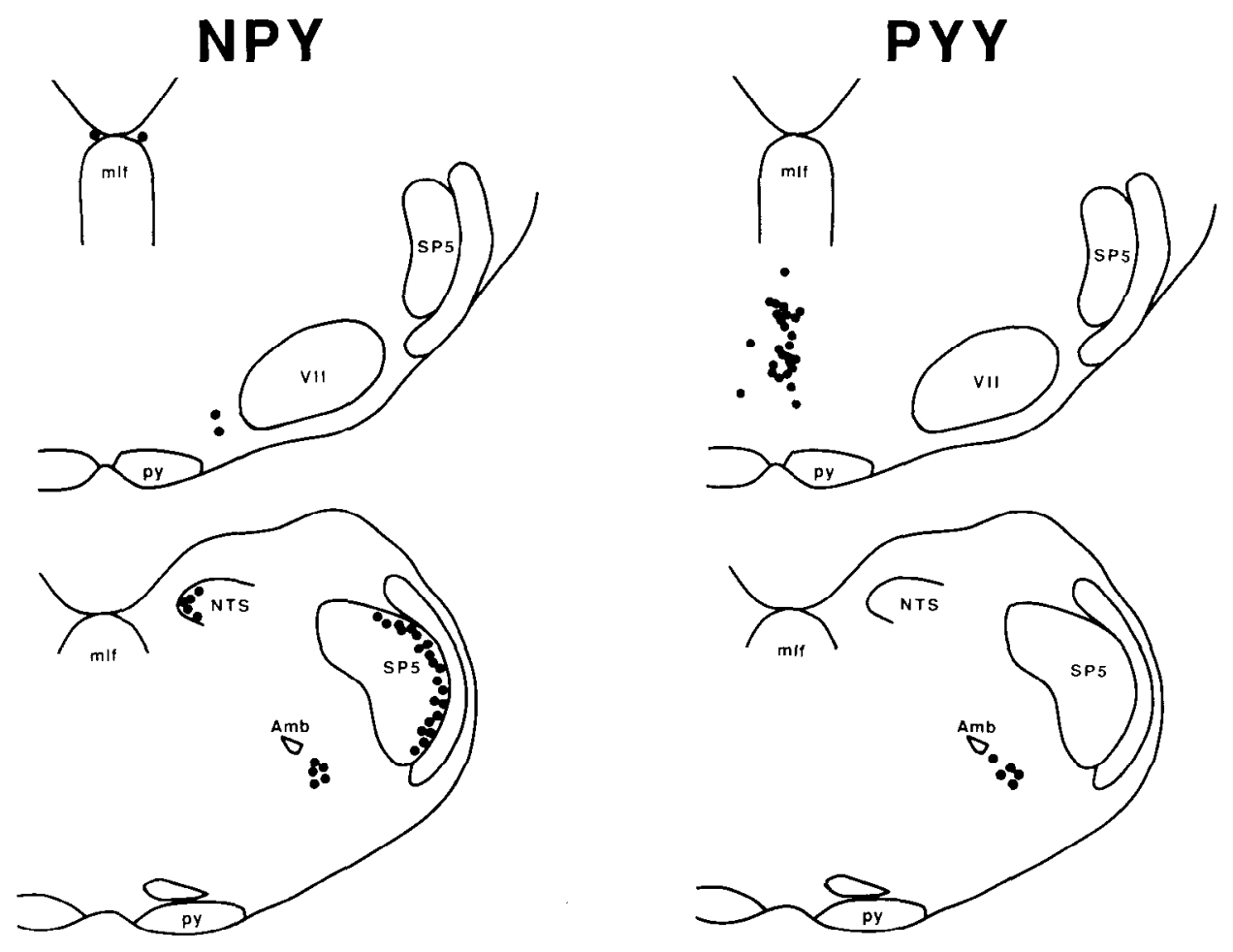

Figure 4. A schematic diagram comparing the distribution of PYY- and NPY-positive neurons in the medulla. The left diagrams show the location of NPY-positive neurons in rostral ( $u p$ per) and caudal (lower) medulla, while the right depicts the location of PYYpositive neurons at these two levels. In the rostral medulla, NPY-positive neurons are found only occasionally in the dorsal midline region ( $\mathrm{C} 3$ adrenaline neurons) and medial to the facial nucleus (VII; $\mathrm{Cl}$ adrenergic neurons). Caudally, NPY-positive neurons are found in the superficial layer of the spinal trigeminal nucleus (SP5), in the medial nucleus of the solitary tract (NTS), and in $\mathrm{Al}$ noradrenergic cells ventral to the ambiguus nucleus $(A m b)$. On the other hand, PYY-positive neurons are only found in rostral medulla on the midline and caudally in the area of noradrenergic $A 1$ neurons. It is not known if the caudally located PYY-positive neurons are $A l$ adrenergic neurons; if so, they represent only a subpopulation since their numbers are much fewer than those cells found to be noradrenergic. $m l f$, medial longitudinal fasciculus; $p y$, pyramidal tract. of their somatic area covered by grains, while the endocrine cells of the colon had $70 \%(195.8 \pm 48.8)$ of their cell area covered by grains. Background staining was less than $1 \%$.

In situ hybridization using the NPY probe

In all of the above PYY experiments, alternate sections of each tissue were processed using the NPY probe. The distribution of labeled neurons in the CNS correlated to previous in situ hybridization studies showing great numbers of neurons in. numerous areas of the CNS including the spinal cord, medulla (Fig. 6), hypothalamus, thalamus, amygdala, hippocampus (Fig. 7 ), and the cerebral cortex. However, no NPY hybridization could be detected in the midline region of the medulla that contained PYY-positive neurons in alternate sections, although NPY-positive neurons were seen in other regions of the medulla including all of the caudal catecholamine cell groups including the $\mathrm{A} 1, \mathrm{~A} 2, \mathrm{~A} 3, \mathrm{C} 1, \mathrm{C} 2$, and $\mathrm{C} 3$ cell groups (Dahlström and Fuxe, 1964; Hökfelt et al., 1974) (Fig. 6), the spinal trigeminal nucleus, and the inferior olivary complex.

Examination of the other peripheral organs (listed above) revealed specific hybridization with the NPY probe only in the intestine (Lundberg et al., 1984) and the adrenal gland (Fig. 5F). There was no apparent hybridization in cells of the mucosal layers of the intestine, but labeled cells (presumably neurons) were always seen in the submucosal layer, mainly in the rostral small intestine (Fig. $7 D$ ). Large cells within the adrenal medulla also stained positive with the NPY probe. If sections of the adrenal medulla were allowed to expose for a long period of time (4 weeks), slight labeling was detected over larger numbers of cells in the adrenal medulla.

Examination of ganglia revealed very strong NPY hybridization in the sympathetic ganglia (superior cervical) (Fig. $5 B$ ), but no specific hybridization was seen in either dorsal root $(C 7)$ or nodose ganglia. However, numerous strongly labeled cells were seen in dorsal root ganglia whose afferent axons had been previously transected 7 or $28 \mathrm{~d}$ prior to removal.

\section{In situ hybridization using the PP probe}

No specific hybridization was detected with either of the PP probes in any part of the CNS or in any peripheral ganglia (normal or cut) even following extended exposure times. Strong hybridization was observed in control sections of pancreas processed on the same slide.

\section{Northern blot analysis}

PolyA + RNA extracted from the medulla, frontal cortex, cerebellum, and distal colon was hybridized with the PYY and NPY oligonucleotide probes (Fig. 8). PYY probe revealed a single strong band of the appropriate size (Leiter et al., 1987) in the lane containing colon mRNA, but no specific hybridization could be detected in any of the lanes containing brain RNA. Hybridization with the NPY-specific probe revealed a heavy band in the lanes containing medulla and cortex RNA and no corresponding signal in the lanes containing cerebellar or colon RNA.

Figure 3. PYY in situ hybridization. A, A dark-field photomontage of the rostral medial medulla showing the intense hybridization seen in neurons on the midline of the medulla. These are the same neurons shown in Figure 2. $B$. A high-power bright-field photomicrograph of a Nissl-counterstained section of the rostral medulla showing silver grain accumulation over cell bodies. $C, A$ high-power photomicrograph of neurons in the caudal lateral medulla (Al region) that exhibited weak hybridization with the PYY probe. D, A dark-field photomicrograph of the colon demonstrating intense hybridization over endocrine cell. $E, A$ high-power photomicrograph of a Nissl-counterstained section of the colon showing hybridization over luminal (endocrine) cells. $S M$, Submucosal layer; $M$, mucosal layer. Scale bars: $A$ and $D, 100 \mu \mathrm{m} ; B, C$, and $E, 50 \mu \mathrm{m}$. 

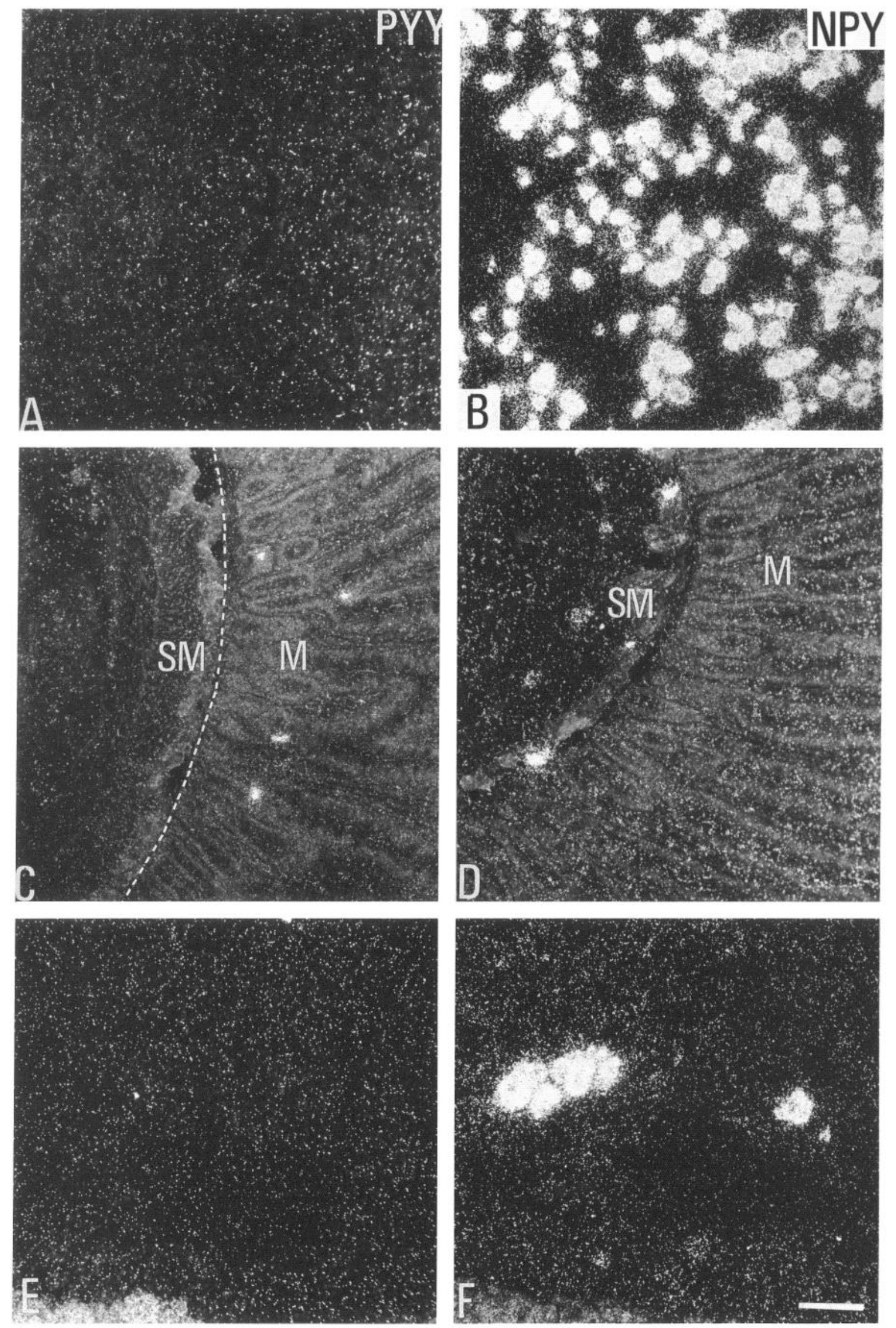

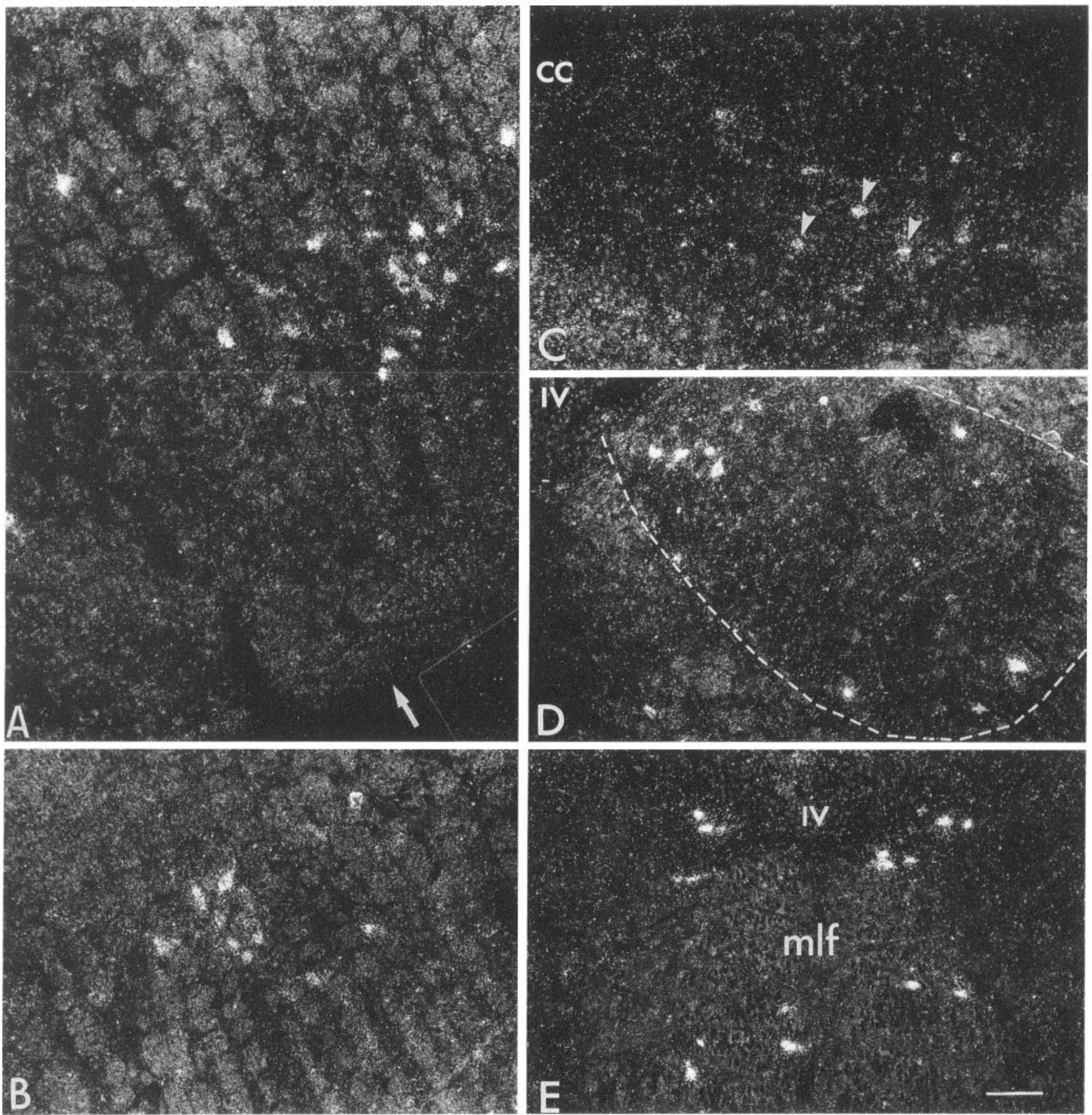

Figure 6. NPY hybridization in the medulla. A, A dark-field photomontage of NPY-positive neurons seen in the ventrolateral rostral medulla (C1 region; arrow indicates the ventral surface of the medulla). NPY-positive neurons were also seen in the caudal ventrolateral medulla (in A1 noradrenergic neurons; $B$ ), the commissural nucleus of the solitary tract (C2/A2 region, $C$ ), the rostral nucleus of the solitary tract (enclosed in dashed line, $D$ ), and in the dorsomedial rostral medulla (the $\mathrm{C} 3$ region, $E$ ). $C C$, central canal; $I V$, fourth ventricle; $m l f$, medial longitudinal fasciculus. (Arrowheads indicate labeled cells.) Scale bar, $100 \mu \mathrm{m}$.

Figure 5. Comparison of PYY $(A, C, E)$ and NPY $(B, D, F)$ hybridization in the superior cervical (sympathetic) ganglia $(A$ and $B)$, the small intestine $(C$ and $D)$, and the adrenal medulla $(E$ and $F)$. The PYY probe failed to show any specific hybridization in sympathetic ganglia, while the NPY probe revealed numerous heavily labeled neurons. In the small intestine, the PYY probe labeled only a few cells in the mucosal layer $(M)$, while the NPY probe labeled presumable enteric neurons in the submucosal $(S M)$ and muscular (not shown) layers. No specific labeling of the adrenal medulla was seen with the PYY probe $(E)$, while the NPY probe labeled scattered large cells in the medulla $(F)$. Scale bar, $100 \mu \mathrm{m}$. 

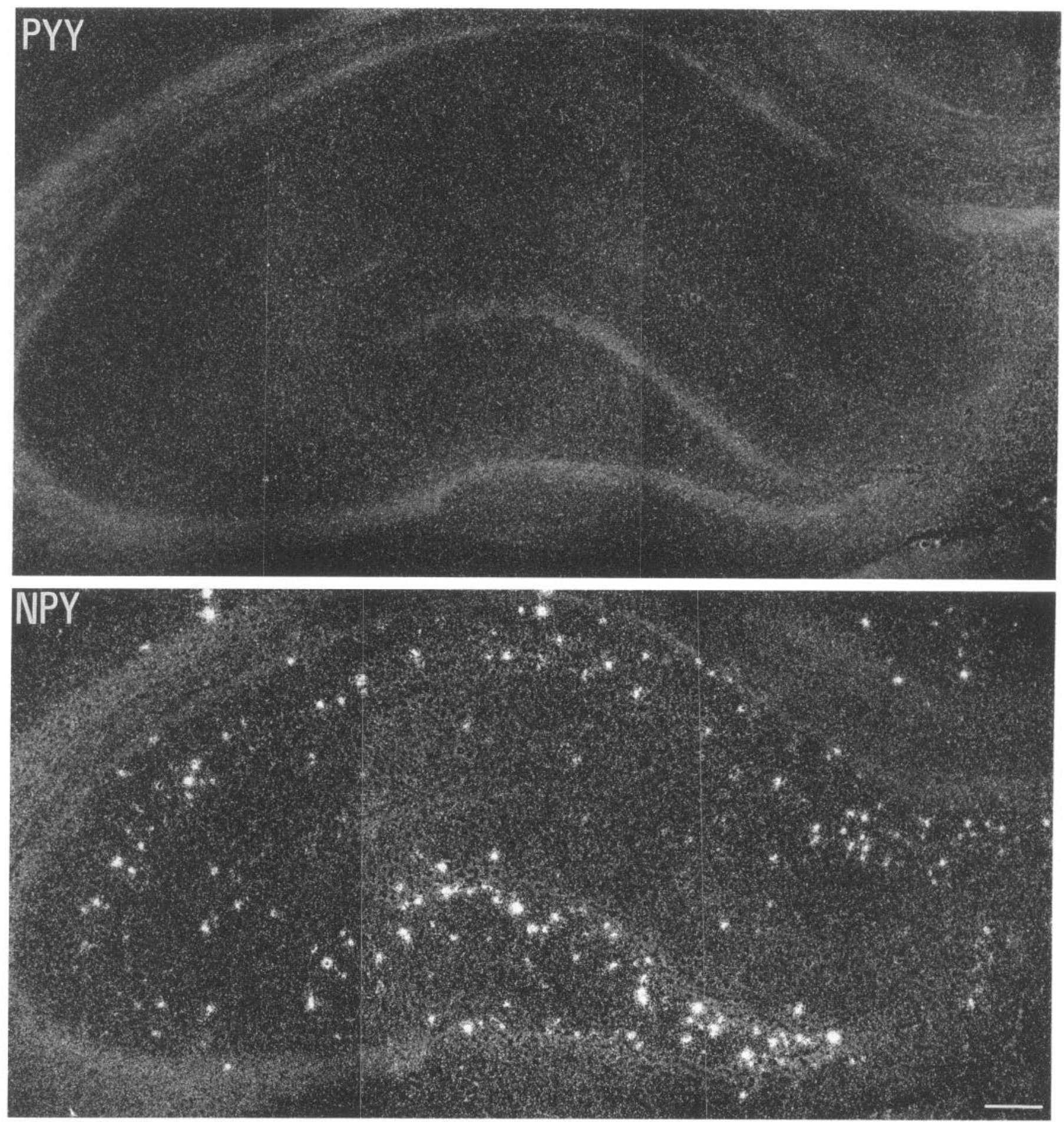

Figure 7. Dark-field photomontages comparing hybridization of PYY and NPY in adjacent sections of the dorsal hippocampus. No hybridization is apparent with the PYY probe, but intense labeling can be seen with the NPY probe, particularly in the dentate gyrus. Scale bar, $100 \mu \mathrm{m}$.

The PYY and NPY mRNA bands were of similar size (figures are aligned at the origins), in agreement with previous work (Larhammar et al., 1987; Leiter et al., 1987). In an additional set of experiments (not illustrated), blots of total RNA from the same tissues as above were probed with cDNA probes to PYY and NPY (see Fig. 1). These blots were identical to the ones presented here although a faint band was seen in the cerebellar lane using the NPY probe. This is likely due to a cerebellar dissection $(n=20)$ that contained a portion of the medulla.

\section{Discussion}

We show here by in situ hybridization that under normal conditions (without colchicine) some neurons in the rat CNS express PYY mRNA. In situ hybridization experiments with the NPY probe revealed large numbers of NPY-containing neurons in the CNS, the sympathetic ganglia as well as in neurons of the upper digestive tract. Northern blot experiments also support the wide spread distribution of NPY in the rat CNS (see also 


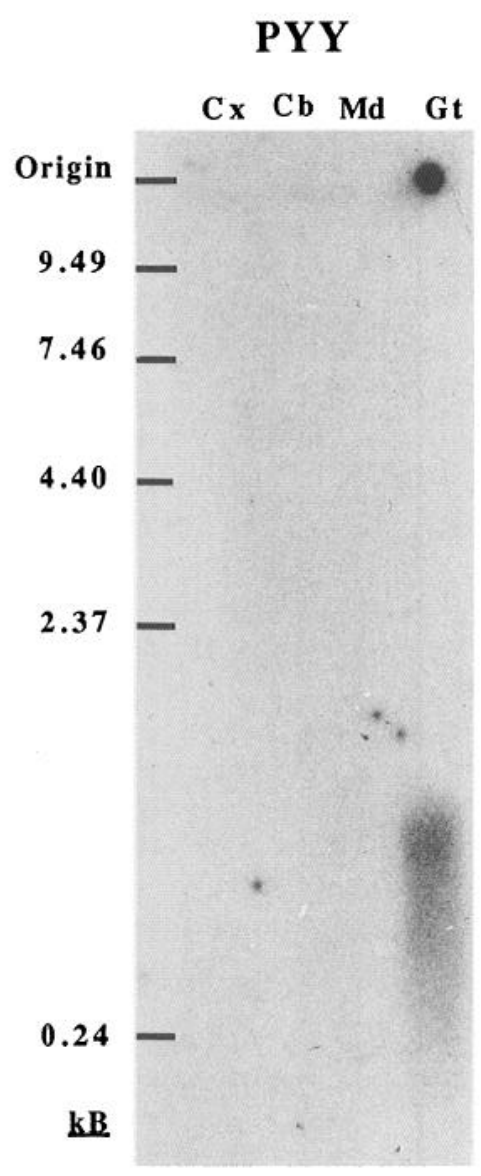

\section{NPY}

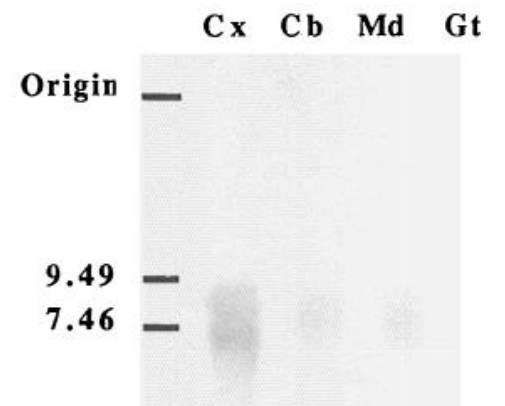

Figure 8. Film autoradiograms of Northern-blotted polyA ${ }^{+}$RNA from the cerebral cortex $(C x)$, cerebellum $(C b)$, medulla $(M d)$, and the distal large intestine $(G t)$ hybridized with the NPY and PYY oligonucleotide probes. The numbers to the left of each blot correspond to the location of size marker RNAs (in kilobases). Hybridization of filters with the PYY probe produced a single band of the appropriate size in the lane containing gut RNA, while no hybridization could be detected in RNA from other tissues. In filters hybridized with the NPY oligonucleotide probe, a strong band was present at the expected size for NPY mRNA in the lanes containing cerebral cortex and medulla RNA, while no corresponding band was found in the lanes containing cerebellar or gut RNA. The weak large-sized bands of atypical shape are probably due to contamination of the polyA ${ }^{+}$RNA.

Larhammar et al., 1987). These results demonstrate that at least two members of the NPY family are synthesized by neurons in the rat brain. In contrast, no PP mRNA could be detected.

While no NPY, PYY, or PP was found in dorsal root ganglia of normal rats, a recent report has shown that peripheral nerve cuts induce NPY immunoreactivity in primary sensory neurons of the dorsal root ganglia (Wakisaka et al., 1991), and this is confirmed here showing expression of NPY mRNA. It appears, however, that peripheral nerve cuts do not enhance (or induce) significant expression of PYY or PP mRNA in dorsal root ganglia.

\section{$P P$-related peptides cannot be reliably distinguished by immunological methods}

When comparing the present with previous studies based on immunological methods, it seems likely that in many of the latter studies cross-reactivity may be responsible for false positive results. Two previous immunocytochemical studies agree with the present results, since in both cases a collection of PYYimmunoreactive neurons were detected in the midline of the rostral medulla (Broomé et al., 1985; Ekman et al., 1986). In contrast, reports indicating that this same area contains NPY(Chronwall et al., 1985; de Quidt et al., 1990) and PP- (Olschowka et al., 1981) immunoreactive cells may be inaccurate.

The observations that the sympathetic ganglia contained PYY(Häppölä et al., 1990) or PP- (Olschowka and Jacobowitz, 1983) like immunoreactivity also appear to be a result of cross-reactivity. It seems likely that the antiserum used in these studies cross-reacted with NPY, which is present in large quantities in sympathetic ganglia (Lundberg et al., 1984). This may also be true with regard to the adrenal medulla (Gaumann et al., 1989).

Taken together, the above discrepancies between the immunocytochemical studies and the in situ hybridization experiments demonstrate the usefulness of comparing the in situ hybridization technique with immunocytochemistry in discriminating the cellular expression of closely related products. It should, however, be noted that our conclusions from in situ hybridization partially rest on negative results, a situation that should always be interpreted with caution. Finally, the present results were obtained without the use of colchicine, as is required in immunocytochemical studies examining the distribution of neuronal somata containing NPY family of peptides. Since colchicine, like axotomy (see above), may influence peptide synthesis (Cortés et al., 1990), our results show that PYY is synthesized in the normal rat brain.

\section{The PYY system is one of the smallest peptide systems in the CNS}

Although we examined numerous sections from all levels of the CNS at long exposure times, we failed to detect any PYY mRNA expression outside the two cell groups in the medulla oblongata, suggesting that this collection of PYY neurons is one of the most discrete neurochemically identified groups of neurons in the rat brain. This conclusion is further supported by the negative Northern blot data. The amount of PYY mRNA in the pooled medial medulla oblongata, as well as in the other brain regions, was below the detectable level of our Northern blot analyses contrasting with the very high levels of NPY mRNA. In addi- 

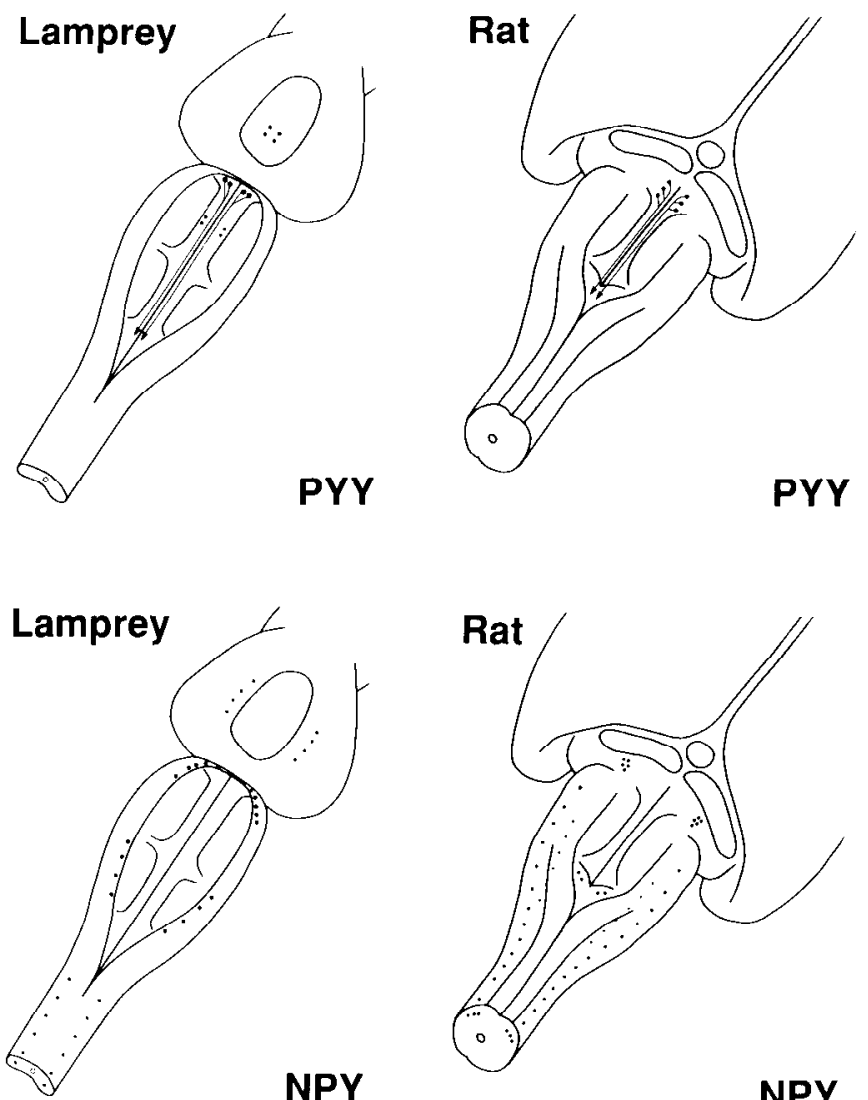

Figure 9. Comparison of NPY-related peptides in lamprey and rat: a schematic diagram comparing the brainstem and spinal cord distribution of NPY and PYY in the rat and their presumed homologs in the lamprey. In the diagrams of rat brain, the cerebellum has been removed. In the rat, there is a collection of large bulbospinal PYY neurons on the midline in the rostral brainstem. A similar collection of large bulbospinal neurons that are PYY immunoreactive are also found around the midline in the rostral brainstem of the lamprey (Brodin et al., 1989). The NPY system in the rat and lamprey have a wider distribution, present mainly lateral to the midline, throughout the brainstem and spinal cord. NPY cells found in the dorsal medulla ( $\mathrm{C} 3$ adrenergic cell group) have been omitted from the diagram.

tion, previous investigators have failed to detect significant levels of PYY in brain extracts (Miyachi et al., 1986). It is interesting to note that the few central PYY neurons in the rat medulla appear to synthesize a relatively large quantity of PYY mRNA (greater amounts of mRNA per cell than NPY neurons). This conclusion is based on two observations: when alternate sections of the brainstem were processed for NPY and PYY and exposed together with probes of the same length, GC ratio, and radioactive end labeling, only PYY hybridization was visible. The NPY signal generally required a much longer exposure time to be visible, indicating that the NPY neurons probably synthesize fewer mRNA molecules per cell. In addition, when the total grain density over neurons in the medulla was compared to that seen over the endocrine cells of the colon, which are known to produce large quantities of peptide, it was found that the neurons had comparably high, although fewer, numbers of grains.

The PYY and NPY systems may have been conserved throughout vertebrate evolution

Retrograde tracing experiments performed in our laboratory have shown that the medial group of PYY neurons has a spinal projection (V. Holets and T. Hökfelt, unpublished observation). The fact that the rat brain contains a reticulospinal PYY system may appear to be of limited interest in view of the vast number of reticulospinal peptidergic systems so far identified. However, our comparative studies of a cyclostome (Lampetra fluviatilis), which diverged from the main vertebrate line about 450 million years ago, suggest that the reticulospinal PYY system may have persisted throughout most of the vertebrate phylogeny. We have recently isolated clones from a brain/spinal cord cDNA library of $L$. fluviatilis, which encodes two different PP-related peptides (Söderberg et al., 1991). Their deduced amino acid sequences indicate that they may correspond to NPY and PYY (cf. Larhammar et al., in press). This supports our previous immunohistochemical evidence for two distinct PP-containing neuron systems in the lamprey brainstem (Brodin et al., 1989). One rather widespread system was found to react with NPY and PP antisera, and a more restricted set of neurons including reticulospinal neurons reacted with PYY and PP antisera. Preliminary in situ hybridization experiments in lamprey have shown that these two patterns of immunoreactivity correspond to the cloned putative lamprey forms of NPY and PYY, respectively (V. A. Pieribone and L. Brodin, unpublished observation). It is striking to note that the location and projection of the PYY cells in the rat brainstem are virtually identical to that of the presumed PYY-containing cells in the lamprey (Fig. 9). In both animals, NPY-immunoreactive neurons and fibers are abundant in the brainstem and spinal cord (dorsal horn; $c f$. also amphibians, Danger et al., 1985), whereas these regions contain only a sparse PYY innervation derived from a small cell cluster in the rostromedial medulla. Thus, at least two PP-related peptides are expressed in the brains of both a cyclostome and a mammal, and it seems likely that their functions have been partly retained. This is as yet the most striking resemblance between peptidergic neuron systems to be observed in a mammal and a cyclostome (for review, see Brodin and Grillner, 1990).

\section{Are there PPY-selective receptors in the CNS?}

Two types of NPY/PYY receptors have been identified in mammalian tissues using autoradiography as well as biochemical and physiological assays (Wahlestedt et al., 1985; Inui et al., 1988; Leslie et al., 1988; Walker et al., 1988; Schwartz et al., 1989; Michel et al., 1990). Studies of the structure-function relationship of NPY and PYY suggest that only the N-terminal and C-terminal regions (residues $1-6+18-36$ and $25-36$, respectively) are important for receptor binding, whereas the 7-17 fragment can be deleted without apparent effects on the binding properties (Krstenansky et al., 1989; Michel et al., 1990). This may explain why the known receptors cannot distinguish well between PYY and NPY, which have similar amino acid sequences in their $\mathrm{N}$ - and $\mathrm{C}$-terminals, whereas they differ most markedly in their midportion (residues 13-18). However, it seems rather unlikely that two distinct peptide systems with related peptides would have evolved if there would be no difference between their target receptors. Therefore, we speculate that additional receptor subtypes selective for either NPY or PYY exist. This is supported by recent intracellular recording experiments in rat locus coeruleus cells, which are hyperpolarized by NPY application, but were unresponsive to PYY (V. A. Pieribone, unpublished observation). If PYY-selective receptors are present in the CNS, they would be expected to occur only in restricted areas of the lower brainstem (not including the locus coeruleus) and spinal cord (see above). Recent comparative 
studies of different lower vertebrate NPYs (Larhammar et al., in press) have shown that the midportion 13-18 region of NPY is highly conserved betwecn specics, indicating biological significance. It therefore seems reasonable to postulate that the binding to putative NPY - and PYY-selective receptors would involve the midportion regions of these peptides.

It will be difficult to assess the exact role of the PYY system in the rat, but the presumed homology with the lamprey system provides a unique opportunity to utilize precise physiologic methods, such as paired intracellular recordings, to characterize in the lamprey the function of a conserved peptide system (cf. Brodin and Grillner, 1990).

\section{References}

Brodin L, Grillner S (1990) The lamprey CNS-an experimentally amenable model for studies of synaptic interactions and integrative functions. In: Preparations of vertebrate central nervous system in vitro. (Jansen $\mathrm{H}$, ed), pp 53-153. New York: Wiley.

Brodin L, Rawitch A, Taylor T, Ohta Y, Ring H, Hökfclt T, Grillner S, Terenius L (1989) Multiple forms of pancreatic polypeptiderelated compounds in the lamprey CNS: partial characterization and immunohistochemical localization in the brain stem and spinal cord. J Neurosci 9:3428-3442

Broomé M, Hökfelt T, Terenius L (1985) Peptide YY (PYY)-immunoreactive neurons in the lower brain stem and spinal cord of rat. Acta Physiol Scand 125:349-352.

Chronwall BM, DiMaggio DA, Massari VJ, Pickel VM, Ruggiero DA, O'Donohue TL (1985) The anatomy of neuropeptide-Y-containing neurons in the rat brain. Neuroscience 15:1159-1181

Cortés R, Ceccatelli S, Schalling M, Hökfelt T (1990) Differential effects of intracerebroventricular colchicine administration on the expression of mRNAs for neuropeptides and neurotransmitter enzymes, with special emphasis on galanin: an in situ hybridization study. Synapse 6:369-391.

Dagerlind Å, Friberg K, Bean AJ, Hökfelt T (in press) Sensitive mRNA detection using unfixed tissue: combined radioactive and nonradioactive in situ hybridization histochemistry. Histochemistry, in press.

Dahlström A, Fuxe K (1964) Evidence for the existence of monoamine-containing neurons in the central nervous system. 1 . Demonstration of monoamines in the cell bodies of brain stem neurons. Acta Physiol Scand 62:5-55.

Danger JM, Guy J, Benyamina M, Jégou S, Leboulenger F, Coté J, Tonon MC, Pelletier G, Vaudry H (1985) Localization and identification of neuropeptide Y (NPY)-like immunoreactivity in the frog brain. Peptides 6:1225-1236.

de Quidt ME, Emson PC (1986) Distribution of neuropeptide Y-like immunoreactivity in the rat central nervous system. II. Immunohistochemical analysis. Neuroscience 18:545-618.

de Quidt ME, Kiyama H, Emson PC (1990) Pancreatic polypeptide, neuropeptide $Y$ and peptide $Y Y$ in central neurons. In: Handbook of chemical neuroanatomy, Vol 9; Neuropeptides in the CNS, Pt II (Bjöklund A, Hökfelt T, Kuhar MJ, eds), pp 287-357. Amsterdam: Elsevier.

DiMaggio DA, Chronwall BM, Buchanan K, O'Donohue TL (1985) Pancreatic polypeptide immunoreactivity in rat brain is actually neuropeptide $Y$. Neuroscience 15:1149-1157.

Ekman R, Wahlestedt C, Böttcher G, Sundler F, Håkanson R, Panula $P$ (1986) Peptide YY-like immunoreactivity in the central nervous system of the rat. Regul Pept 16:157-168.

Gaumann DM, Yaksh TL, Tyce GM, Stoddard SL (1989) Adrenal vein catecholamines and neuropeptides during splanchnic nerve stimulation in cats. Peptides 10:587-592.

Häppölä O, Wahlestedt C, Ekman R, Soinila S, Panula P, Håkanson R (1990) Peptide YY-like immunoreactivity in sympathetic neurons of the rat. Neuroscience 39:225-230.

Hökfelt T, Fuxe K, Goldstein M, Johansson O (1974) Immunohistochemical evidence for the existence of adrenaline neurons in the rat brain. Brain Res 66:235-251.

Inui A, Oya M, Okita M, Inoue T, Sakatani N, Morioka H, Shii K, Yokono K, Mizuno N, Baba S (1988) Peptide YY receptors in the brain. Biochem Biophys Res Commun 150:25-32.
Kimmell JR, Pollock HG, Hazelwood RL (1975) Isolation and characterization of a new pancreatic polypeptide hormone. J Biol Chem 250:9369-9376.

Krstenansky JL, Owen TJ, Buck SH, Hagaman KA, McLean LR (1989) Centrally truncated and stabilized porcine neuropeptide $Y$ analogs: design, synthesis, and mouse brain receptor binding. Proc Natl Acad Sci USA 86:4377-4381.

Larhammar D, Ericsson A, Persson H (1987) Structure and expression of the rat neuropeptide Y gene. Proc Natl Acad Sci USA 84:20682072.

Larhammar D, Söderberg C, Blomqvist A (in press) Evolution of the neuropeptide $Y$ family of peptides. In: Neuropeptide $Y$ (Wahlestedt $\mathrm{C}$, Colmers $\mathrm{W}$, eds), in press. Clifton, $\mathrm{NJ}$ : Humana.

Leiter AB, Toder A, Wolfe HJ, Taylor IL, Cooperman S, Mandel G, Goodman RH (1987) Peptide YY. Structure of the precursor and expression in exocrine pancreas. J Biol Chem 262:12984-12988.

Leslie RA, McDonald TJ, Robertson HA (1988) Autoradingraphic localization of peptide $\mathrm{YY}$ and neuropeptide $\mathrm{Y}$ binding sites in the medulla oblongata. Peptides 9:1071-1076.

Lin TM, Chance RE (1974) Candidate hormones of the gut: bovine pancreatic polypeptide (BPP) and avian pancreatic polypeptide (APP). Gastroenterology 67:737-738.

Lundberg JM, Terenius L, Hökfelt T, Tatemoto K (1984) Comparative immunohistochemical and biochemical analysis of pancreatic polypeptide-like peptides with special reference to presence of neuropeptide $\mathrm{Y}$ in central and peripheral neurons. $J$ Neurosci 4:2376-2386.

Michel MC, Schlicker E, Fink K, Boublik JH, Göthert M, Willette RN, Daly RN, Hieble JP, Rivier JE, Motulsky HJ (1990) Distinction of NPY receptors in vitro and in vivo. I. NPY-(18-36) discriminates NPY receptor subtypes in vitro. Am J Physiol 259:E1 31-E139.

Miyachi Y, Jitsuishi W, Miyoshi A, Fujita S, Mizuchi A, Tatemoto K (1986) The distribution of polypeptide YY-like immunoreactivity in rat tissues. Endocrinology 118:2163-2167.

Olschowka JA, Jacobowitz DM (1983) The coexistence and release of bovine pancreatic polypeptide-like immunoreactivity from noradrenergic superior cervical ganglia neurons. Peptides 4:231-238.

Olschowka JA, O'Donohue TL, Jacobowilz DM (1981) The distribution of bovine pancreatic polypeptide-like immunoreactive neurons in rat brain. Peptides 2:309-331.

Paxinos $\mathrm{G}$, Watson $\mathrm{C}$ (1986) The rat brain in stereotaxic coordinates. Sidney: Academic

Schalling M, Hökfelt T, Wallace M, Goldstein M, Filer D, Yamin C Schlesinger DH (1986) Tyrosine 3-hydroxylase in rat brain and adrenal medulla: hybridization histochemistry and immunohistochemistry combined with retrograde tracing. Proc Natl Acad Sci USA 83:6208-6212.

Schwartz TW, Fuhlendorff J, Langeland N, Thøgersen H, Jørgensen JC, Sheikh SP (1989) Y1 and Y2 receptors for NPY - the evolution of PP-fold peptide and their receptors. In: Neuropeptide Y (Mutt V, Fuxe K, Hökfelt T, Lundberg J, eds), pp 143-152. New York: Raven.

Söderberg C, Brodin L, Dahlsirand J, Larhammar D (1991) Cloning of two neuropeptide Y (NPY) related peptides in the river lamprey (Lampetra fluviatilis). Eur J Neurosci [Suppl] 4:2231.

Tatemoto K (1982) Isolation and characterization of peptide YY (PYY), a candidate gut hormone that inhibits pancreatic exocrine secretion. Proc Natl Acad Sci USA 79:2514-2518.

Tatemoto K (1989) Neuropeptide $Y$ : isolation, structure, and function. In: Neuropeptide Y (Mutt V, Fuxe K, Hökfelt T, Lundberg J, eds), pp 13-22. New York: Raven.

Tatemoto K, Carlquist M, Mutt V (1982) Neuropeptide Y-a novel brain peptide with structural similarities to peptide $Y Y$ and pancreatic polypeptide. Nature 296:659-660.

Wahlestedt C, Edvinsson L, Ekblad E, Häkanson R (1985) Neuropeptide $\mathrm{Y}$ potentiates noradrenaline-evoked vasoconstriction: mode of action. J Pharmacol Exp Ther 234:735-741.

Wakisaka S, Kajander KC, Bennett GJ (1991) Increased neuropeptide Y (NPY)-like immunoreactivity in rat sensory neurons following peripheral axotomy. Neurosci Lett 124:200-203.

Walker MW, Ewald DA, Perney TM, Miller RJ (1988) Neuropeptide $\mathrm{Y}$ modulates neurotransmitter release and $\mathrm{Ca}^{2+}$ currents in rat sensory neurons. J Neurosci 8:2438-2446.

Yonekura H, Nata K, Wanatabe T, Kurashina Y, Yamamoto H, Okamoto H (1988) Mosaic evolution of prepropancreatic polypeptide. II Structural conservation and divergence in pancreatic polypeptide gene. J Biol Chem 263:2990-2997. 